Education

et sociétés

plurilingues

\section{Éducation et sociétés plurilingues}

46 | 2019

Varia

\title{
Panorama storico del “Mondo Bilingue": 1951-2010
}

Editoriale

\section{Andrée Tabouret-Keller}

\section{(2) OpenEdition}

\section{Journals}

Edizione digitale

URL: http://journals.openedition.org/esp/3675

DOI: $10.4000 /$ esp.3675

ISSN: 2532-0319

\section{Editore}

Centre d'Information sur l'Éducation Bilingue et Plurilingue

\section{Edizione cartacea}

Data di pubblicazione: 1 juin 2019

Paginazione: 5-6

ISSN: 1127-266X

Notizia bibliografica digitale

Andrée Tabouret-Keller, «Panorama storico del "Mondo Bilingue": 1951-2010», Éducation et sociétés plurilingues [Online], 46 | 2019, Messo online il 01 février 2021, consultato il 01 mars 2021. URL: http:// journals.openedition.org/esp/3675; DOI: https://doi.org/10.4000/esp.3675

Questo documento è stato generato automaticamente il 1 mars 2021

(C) CIEBP 


\title{
Panorama storico del "Mondo Bilingue": 1951-2010
}

\author{
Editoriale
}

Andrée Tabouret-Keller

1 L'associazione internazionale Le monde bilingue fu fondata nel 1951 da ex-resistenti, fra cui Jean-Marie Bressand (1919-2011), che avrebbe poi partecipato anche alla fondazione della Federazione mondiale delle città gemellate nel 1957 (seguito poi da Pierre Mauroy). Nell'ottobre 2001 il primo ministro francese Lionel Jospin accorda il suo patrocinio all'associazione Le monde bilingue in occasione del cinquantesimo anniversario dell'associazione, che doveva essere celebrato a Babilonia. Nel novembre 1999 un progetto di risoluzione sull'educazione bilingue e sul plurilinguismo fu approvato all'unanimità dai 187 Paesi rappresentati alla $30^{\mathrm{a}}$ Conferenza Generale dell'UNESCO. Per la prima volta l'Organizzazione delle Nazioni Unite per la Scienza e la Cultura prendeva posizione sul tema controverso dell'insegnamento delle lingue e definiva le grandi linee di una politica linguistica pluralistica basata su un'educazione bilingue precoce. Una conferenza internazionale sul plurilinguismo avrebbe dovuto svolgersi in Iraq, a Babilonia, nell'ottobre 2001, con il patrocinio dell'UNESCO e della Lega degli Stati Arabi. Rimandata sine die a causa degli eventi dell'11 settembre (attacco alle torri gemelle di New York), sarà sostituita nell'ottobre 2002 dalla Conferenza di Delémont, capoluogo del Giura svizzero, sullo stesso tema e godrà, fra gli altri, del patrocinio del ministro francese dell'Istruzione, Jack Lang.

2 In agosto 2001, Jean-Marie Bressand precisa sul giornale Le Monde le sue convinzioni di sempre, affinché ciascuno sia bilingue all'inizio della sua vita, plurilingue in seguito:

1. Un bambino bilingue ne vale due, o perfino tre;

2. per questo occorre insegnargli la seconda lingua molto presto, cominciando se possibile fin dalla gestazione;

3. avere genitori di lingue diverse è un tesoro per il bambino, purché ognuno di loro parli esclusivamente la propria lingua quando si rivolge al bambino che, in tal modo, diventerà bilingue; 
4. i bambini di genitori monolingui devono acquisire una seconda lingua, qualsiasi essa sia, straniera (preferibilmente quella del vicino) o regionale, fin dal giardino d'infanzia, secondo i principî dell'educazione bilingue precoce ed immersiva, vale a dire un'acquisizione inizialmente esclusivamente orale e ricreativa, quella di cui un tempo godevano i bambini che disponevano di una governante straniera;

5. in effetti, grazie ad assistenti, maestri o professori, venuti da fuori, gli scolari apprenderanno alcune materie in programma non più in una sola, bensì in due lingue, prendendo così due piccioni con una fava;

6. in simili condizioni il bambino bilingue svilupperà grandi facilità sia per imparare altre lingue che per continuare gli studi in tutta la sua formazione futura, fino all'insegnamento universitario.

Paradossalmente la maggior parte dei piccoli Francesi non beneficeranno di queste facilitazioni, perché, a causa di alcuni sindacati e del Consiglio di Stato, vengono esclusi dall'educazione bilingue:

1. in mezzo secolo, tre ministri dell'Istruzione hanno tentato di fare un'eccezione alla regola non scritta che si oppone ad ogni progresso in quest'ambito: André Marie agli inizi degli anni Cinquanta, Alain Savary nel 1982-83 e Jack Lang nel 2001;

2. poiché l'educazione bilingue immersiva esiste solamente nelle scuole associative regionali, le misure prese da Jack Lang avevano lo scopo di integrare la formula immersiva nel settore pubblico.

4 Per quanto riguarda l'insegnamento in lingua regionale, si può dire che si avvantaggi di una cultura regionale in linea con la storia e la tradizione. I piccoli bilingui alsaziani, baschi, bretoni, catalani, corsi, fiamminghi o occitani dovrebbero raggiungere in breve tempo i piccoli monolingui a cui lo Stato giacobino fa perdere un gran numero d'ore a ripetere stentatamente un inglese standard in 'lezioni di lingua' dai risultati contestabili.

5 In quest'intervento che precede di qualche anno la sua morte, si può sentire tutta la delusione e la rabbia del militante del bilinguismo e degli scambi fra i popoli. Da allora il bilinguismo è entrato nello nelle scuole, anche in Francia. La nostra piccola rivista Educazione e società plurilingui esce semestralmente dal 1996 e rende conto della straordinaria diversità delle situazioni linguistiche, della loro complessità e degli sforzi, talvolta sovrumani, per difendere la causa del plurilinguismo, sia nella società che nella sfera dell'educazione.

\section{INDICE}

Keywords : Jean-Marie Bressand, bilingual world, activist for bilingual education, Unesco, U.N. Parole chiave : Jean-Marie Bressand, mondo bilingue, attivista del bilinguismo, Unesco, ONU 
AUTORE

ANDRÉE TABOURET-KELLER

Université de Strasbourg (France) 